\title{
Tensões e contradições no cotidiano lúdico do catolé
}

\author{
Emília Amélia Pinto Costa da Silva \\ Eduardo Ribeiro Dantas
}

LEMOS, EMBC., DANTAS, ER., and CHAO, CHN., orgs. De portas abertas para o lazer: a cultura lúdica nas comunidades de Bairro [online]. Campina Grande: EDUEPB, 2009. 184 p. ISBN 978-85-

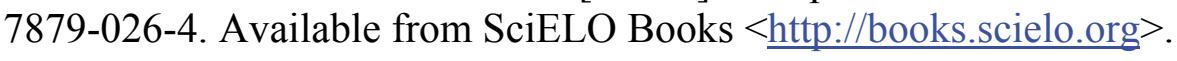

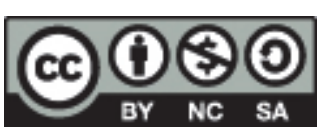

All the contents of this work, except where otherwise noted, is licensed under a Creative Commons Attribution-Non Commercial-ShareAlike 3.0 Unported.

Todo o conteúdo deste trabalho, exceto quando houver ressalva, é publicado sob a licença Creative Commons Atribuição Uso Não Comercial - Partilha nos Mesmos Termos 3.0 Não adaptada.

Todo el contenido de esta obra, excepto donde se indique lo contrario, está bajo licencia de la licencia Creative Commons Reconocimento-NoComercial-CompartirIgual 3.0 Unported. 


\title{
Tensões e contradições no cotidiano lúdico do catolé
}

\author{
Emília Amélia Pinto Costa da Silva \\ Eduardo Ribeiro Dantas
}

Este artigo tem como proposta discutir o cotidiano lúdico do bairro do Catolé, localizado na cidade de Campina Grande - PB. Para tanto, partiremos do surgimento do bairro, contextualizando sua formação. Em seguida, iremo-nos concentrar na sua situação atual, em se tratando das experiências de lazer de seus moradores.

O bairro do Catolé está localizado na Zona Sul da cidade, possuindo segundo o Instituto Brasileiro de Geografia e Estatística - IBGE (2002), 17.034 habitantes, sendo um dos três bairros mais populosos de Campina Grande.

O primeiro nome dado ao bairro foi "Sítio Baixa de Pau", pois encontrava-se em uma área mais isolada da cidade, sem muito desenvolvimento. Possuía algumas casas de farinha e o resto era um grande roçado. Posteriormente, na medida em que foi crescendo, passou a ser chamado Catolé. Após a construção do maior estádio de futebol da cidade, o "Amigão", no início da década de 70, o processo de pavimentação das ruas do bairro contribuiu muito para sua ampliação (JORNAL DA PARAÍBA, 2006).

Situa-se em uma área que vem se valorizando muito do ponto de vista imobiliário, chegando a possuir, hoje em dia, um dos metros-quadrados mais caros da cidade (JORNAL DA PARAÍBA, 2006). 
Em um contexto geral, as condições socioeconômicas do bairro atualmente são bastante heterogêneas, mesmo que a renda média mensal dos seus moradores, calculada em R $\$ 970,34$ pelo IBGE (2002), seja mais alta do que a encontrada em muitos outros bairros da cidade.

0 crescimento desordenado do bairro revela, em cada rua e esquina não saneadas das espécies de guetos que ali proliferaram, as tensões e contradições sociais próprias aos grandes centros urbanos das sociedades contemporâneas.

Para pensarmos a gestão do esporte recreativo e do lazer em um contexto tão contraditório, levando em conta a necessidade de políticas públicas, sejam elas intersetoriais ou não, optamos por uma compreensão mais horizontal da relação entre o poder público e os mais diversos grupos da sociedade civil organizada, na qual os interesses coletivos se sobrepõem aos individuais e as diferenças sociais são minimizadas em favor da vida em comum.

Compreensão esta, em que a mobilização social surge como um conceito chave para a superação do paternalismo político que ainda insiste em se perpetuar enquanto lógica de administração da vida pública, comprometendo o exercício da cidadania e o estabelecimento de uma ordem democrática legítima (TORO; WERNECK, 2007).

Seguindo o pensamento de pesquisadores que entendem a participação popular como um elemento de inovação em gestão pública nas mais diversas áreas, passamos a descrever agora a situação do esporte recreativo e do lazer no bairro do Catolé, tendo como ponto de partida as políticas públicas que atingem os moradores do bairro e algumas de suas comunidades organizadas.

\section{Discutindo as políticas públicas de lazer no Catolé}

De acordo com Chemin (2007), as políticas públicas são os meios pelos quais a Administração do Estado efetiva as disposições constitucionais. Desse modo, compreendemos que as políticas públicas de lazer, têm como função, promover ações que visem garantir o direito ao lazer, através do exercício da cidadania. 
Consideramos, ainda, que as políticas públicas de lazer devem ser constituídas por projetos, programas, leis e outras estratégias, que tenham uma atenção especial com o desenvolvimento das cidades brasileiras, onde no cotidiano da população, o lazer é vivenciado efetivamente.

Até mesmo porque, os espaços e equipamentos públicos de lazer existentes, nos centros urbanos, são adequados à vivência de diversos interesses culturais, podendo ser utilizados pela população em diferentes aspectos. Deste modo, estes ambientes são atraentes por motivo da inexistência de uma determinação da forma de uso, permitindo aos frequentadores utilizá-los da melhor maneira possível (RECHIA, 2008).

Dialogando com o pensamento de Bauman (2009) sobre o espaço público, destacamos ainda que são, nesses locais, que as diversas formas de convivência social emergem, expressas nas dores, alegrias e esperanças da população. De acordo com o autor, no espaço público, a atração e a rejeição da convivência social se entrelaçam, de forma a nos darem a chance de superar ou reforçar as diferenças que nos separam, o que mostra a importância do espaço público para a vida coletiva.

No bairro do Catolé, um dos espaços públicos onde podemos perceber a convivência não só de moradores de diferentes classes sociais, mas também de outras localidades da cidade, é o "Parque da Criança", onde funciona um projeto da Prefeitura Municipal de Campina Grande, chamado "Campina Bem-Estar". Projeto este, que disponibiliza, para os frequentadores do parque, aulas de ginástica, verificação da pressão arterial, verificação de peso e altura, entre outros serviços.

Dentro do parque, localiza-se também uma biblioteca, que é resultado de um projeto do Serviço Social da Indústria - SESI, chamado "A Indústria do Conhecimento", onde a comunidade tem acesso a livros e revistas, além de computadores.

Outras ações de lazer encontradas, no parque, são as aulas de Tai Chi Chuan e Capoeira, que abrindo espaço para qualquer usuário, não estão vinculadas a qualquer projeto ou programa do poder público. 
O espaço do "Parque da Criança" é bastante utilizado para os eventos da cidade, tais como o "Dia da Criança" e o "Domingo no Parque", além de competições e outras ações promovidas pelos órgãos públicos.

Dessa forma, percebemos que o bairro do Catolé recebe um dos espaços de lazer mais movimentados da cidade, que através de seus equipamentos e projetos específicos de lazer, possibilita a vivência lúdica da população de Campina Grande.

Mesmo assim, acreditamos que o "Parque da Criança", por si só, não atende todas as demandas lúdicas da cidade, necessitando de maiores investimentos tanto do ponto de vista estrutural, quanto humano. Como se trata de um local distante até mesmo de certas áreas do bairro, questionamos se ele está sendo apropriado aos moradores mais carentes do Catolé, que social e geograficamente longe do parque, podem estar tendo o seu direito ao lazer comprometido pela falta de um espaço público mais próximo de suas vidas.

Neste sentido, precisamos de maiores reivindicações para a conquista desses espaços, já que as possibilidades de transformação social dependem também da democratização do lazer, que em última análise, está relacionada à democratização do espaço.

\begin{abstract}
Muito embora as pesquisas realizadas na área das atividades desenvolvidas no tempo livre enfatizam a atração exercida pelo tipo de equipamento construído, deve-se considerar que, para a efetivação das características do lazer é necessário antes de tudo, que ao tempo disponível corresponda um espaço disponível (MARCELLINO, 1995, p. 57).
\end{abstract}

Assim sendo, é necessário que a população se envolva na elaboração das políticas públicas de lazer, reivindicando ações que beneficiem a comunidade, em geral, e não apenas segmentos dela. A seguir, iremos discutir as possibilidades de participação popular no Catolé, a partir de elementos identificados em nossa pesquisa de campo. 


\section{Interfaces entre lazer e educação}

Para uma melhor aproximação do bairro, realizamos uma entrevista em uma de suas escolas municipais. A atual gestora está nesta função há quatro anos. Esse cargo foi escolhido através de uma votação entre funcionários em geral, pais e alunos da respectiva escola.

A escola funciona nos três turnos, sendo o turno da noite para educação de jovens e adultos. Apenas um turno é contemplado com aulas de Educação Física, que são alunos da tarde. A diretora expõe que a Secretaria de Educação escolheu o turno da tarde, pois é o horário que tem mais alunos matriculados.

O turno da manhã tá sem professor de Educação Física. Aí a gente fica numa situação, os bichinhos da manhã, os meninos da manhã não tem... é... é... as professoras é que brincam com eles no momento de recreação, na verdade é uma recreação, mas... é... pra Educação Física não tem não para manhã (Presidente da SAB Catolé).

Neste caso, percebemos que a Educação Física, enquanto componente curricular, não está sendo tratada como um dos caminhos que proporcionam uma educação para o lazer, já que para a maioria dos alunos da escola, ela é vivenciada apenas como uma atividade física.

Precisamos que a Educação Física e seus objetivos na escola sejam repensados, para que possam estar colaborando com a reflexividade de seus alunos, no sentido de reforçar o entendimento do lazer como uma dimensão da vida humana. A Educação Física, em apenas um dos turnos, afasta a maioria dos alunos dessa perspectiva, uma vez que, enquanto componente curricular obrigatório da educação básica, ela tem a função de inserir e integrar todos os alunos na cultura corporal do movimento (BETTI; ZULIANI, 2002).

Para suprir as necessidades da escola na área da Educação Física, ela tem uma parceria com o Instituto Alpargatas e o Instituto Camargo Corrêa, através do projeto "Escola Ideal", que tem o objetivo de beneficiar as escolas públicas, fortalecendo o elo da criança com a escola através da Educação Física (INSTITUTO ALPARGATAS, 2008). 
Com a implantação desse projeto, a escola municipal investigada foi contemplada, no ano de 2008, com equipamentos de esporte e lazer até então inexistentes na instituição. Foram doadas, por exemplo, bolas, jogos de xadrez, dominós, damas, bolas de gude e rede de voleibol. Entendemos que as parcerias são importantes para a efetivação do direito ao lazer da população, mas não podemos deixar de lembrar da responsabilidade social do poder público, em ofertar Educação Física de qualidade para a população.

São muitas as dificuldades existentes na escola. No ano de 2009, ela recebeu $\mathrm{R} \$ 4.285,00$, para despesas gerais, tais como, papel, material de limpeza e material escolar. A diretora relata que as crianças da escola são carentes, e algumas delas não têm condições sequer de comprar um caderno.

Outra alternativa para a arrecadação de fundos para a escola, é a organização de bingos. Com o dinheiro arrecadado em um deles foi construído o playground, que trouxe novas possibilidades lúdicas para as crianças, como podemos observar na foto a seguir.

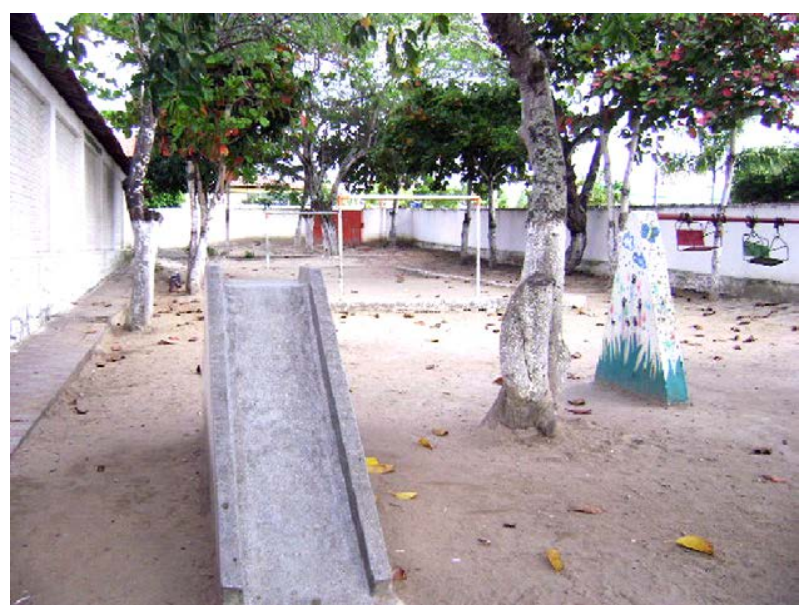

Imagem 01: Playground: novas possibilidades lúdicas

Fonte: Arquivos do GCEM 
Em relação à participação da comunidade na escola, existe o Conselho Escolar, composto por representantes dos alunos, dos pais, dos funcionários e dos professores. Mesmo com muitos pais ausentes, a escola se preocupa com a articulação junto às famílias. Todos os dias, no horário de chegada dos alunos, há uma acolhida, preparada por pais, alunos e professores. Cada dia da semana, há um encarregado na elaboração desse momento, o que torna interessante a participação dos pais, embora todos não estejam presentes.

Percebemos que a participação da população, nas questões escolares, remete mais à qualidade da aprendizagem que os alunos estão tendo, diferentemente da participação popular na Sociedade Amigos do Bairro - SAB Catolé, onde questões, de ordem mais geral do bairro, são colocadas, em pauta, para decisão conjunta dos moradores do bairro. Entendemos, porém, que a escola podia ser utilizada como um canal institucional mais atuante, na reivindicação de políticas públicas de esporte e lazer e não se limitar aos assuntos que envolvem a comunidade escolar.

\section{O lazer para os "Amigos do Bairro Catolé"}

A função social das SABs de Campina Grande é defender os interesses da população do bairro, servindo como mediadora entre os moradores e os governantes. Atualmente, elas são coordenadas pela União Campinense das Equipes Sociais - UCES, que tem o objetivo de orientar e fiscalizar as atividades promovidas pelas entidades associadas, bem como, incentivar seus representantes a construírem políticas públicas que contribuam com o desenvolvimento socioeconômico e o combate a pobreza (UCES, 2009).

A SAB do Catolé teve sua fundação em 1968, possuindo atualmente 609 sócios. Para se associar à SAB, as pessoas devem provar através do comprovante de residência, que são moradoras do bairro, podendo após isso, participar de todas as atividades dos associados, tais como as eleições da sua diretoria. 
A atual gestora comenta que nas eleições passadas, por falta de esclarecimento das delimitações do bairro, um dos moradores foi impedido de votar, por ter um comprovante de residência do bairro Itararé, situado ao lado do Catolé. Este morador precisou entrar na justiça para recuperar seu direito a voto, já que realmente fazia parte do Catolé. Neste caso, observamos que apesar de morar distante da SAB, o morador reconheceu seu direito de reivindicação através deste canal institucional, o que revela que mesmo sem uma participação maciça da população dos bairros, as SABs continuam sendo estruturas significativas para as reivindicações dos moradores de Campina Grande.

A SAB do Catolé possui prédio próprio e no mesmo local funciona o Clube de Mães. São realizadas reuniões frequentes, sendo que para anunciá-las, são expostos, na frente da $\mathrm{SAB}$, cartazes com o horário e a data das mesmas. Também é feita uma divulgação por meio de carro de som nas ruas do bairro.

A pauta da reunião é formulada através do contato que a presidente tem com a população, a partir das sugestões e reclamações que alguns moradores passam para a gestora. Para maior incentivo da participação da população nas assembleias, sempre é convidado algum secretário, vereador ou conselheiro, para chamar a atenção dos sócios, mas mesmo assim, não são todos os associados que comparecem às reuniões.

Segundo a presidente da SAB, os moradores reclamam em relação ao lixo colocado na frente da quadra. "A pauta da reunião é muita queixa do lixo que é colocado, exposto aqui na frente da SAB. Lixo mesmo que é os próprios moradores que coloca. E... a queixa é da segurança, saúde".

Reivindicações que, como pudemos presenciar, são de certa forma atendidas pelo poder público. Durante a nossa pesquisa de campo, a prefeitura da cidade limpou a área solicitada. Dois dias depois, porém, percebemos já uma pequena acumulação de lixo no local, depositado pelos próprios moradores do bairro, o que nos leva a alertar para a necessidade de uma maior educação ambiental da população.

Na primeira visita que fizemos à $\mathrm{SAB}$, a gestora mencionou que seria estipulada uma pequena taxa mensal aos sócios, para um melhor desenvolvimento da instituição. Em uma segunda visita, a gestora in- 
formou que essa taxa até o momento não está sendo cobrada, pela falta de atividades oferecidas pela $\mathrm{SAB}$, o que por si só gera um problema, já que um meio de manter o prédio é cobrar taxas de inscrições quando são oferecidos cursos.

Uma dificuldade citada pela atual gestora é o fato da SAB não possuir nenhum fundo financeiro, além de possuir algumas dívidas que foram deixadas pela gestão passada, que segundo a presidente, passou dezessete anos no poder. A atual gestora está lutando contra um processo, na justiça, para regularizar sua situação e conseguir novas parcerias.

Mas a gente quer limpar esse processo para que a gente possa trabalhar junto com o governo federal, estadual e municipal para desenvolver atividades de lazer, de esporte, na área de educação (Presidente da $S A B$ Catolé).

0 maior problema relatado foi à má condição que o prédio se localiza, necessitando de reformas. Mas, segundo notícia veiculada no site da UCES (2009), a Prefeitura Municipal de Campina Grande comprometeu-se com a construção, ampliação e reforma das sedes das SABs.

Na primeira ida a campo, em uma entrevista com a presidente da SAB Catolé, a presidente relatou um assalto, na $\mathrm{SAB}$, o que ocasionou a suspensão de alguns cursos que eram realizados, como curso de reciclagem e de secretariado. A única atividade desenvolvida era a atuação em parceria com o Programa Saúde da Família - PSF, que desenvolvia seu trabalho, distribuindo medicamentos, verificando a pressão e fazendo o controle do diabetes da população. Mesmo com essa atuação, observavam-se ainda algumas carências na promoção da saúde fornecida pelo PSF, como por exemplo, a falta de medicamentos.

Em outra ida a campo, percebemos novas iniciativas de atividades que são oferecidas para a população. Foi implantado, na SAB, o PróJovem $^{1}$, que é um curso oferecido para os jovens com objetivo de tirálos das ruas. Outra atividade implantada, na SAB, é um curso de evangelização para as crianças, que é realizado em parceria com a igreja Batista. Outro projeto que está para ser implantado na SAB, é o "Perfil"

1 A sede geral do Pró-Jovem em Campina Grande é localizada, no Complexo Desportivo Plínio Lemos, localizado no bairro do José Pinheiro. 
este, tendo a finalidade de oferecer cursos profissionalizantes para os jovens. Nesta perspectiva, compreende-se um avanço nas atividades oferecidas pela $\mathrm{SAB}$, em comparação ao primeiro contato que tivemos com ela.

A atual presidente está desenvolvendo uma pesquisa de opinião junto à população. Desee modo, está tendo contato com os moradores, com o objetivo de conhecer os problemas referentes à saúde, à educação e à infraestrutura, que o bairro enfrenta, para assim, convocar uma sessão com a população, convidando prefeito, vereadores e secretários, na tentativa de solucionar as dificuldades cotidianas.

Em relação às reivindicações populares relacionadas ao esporte recreativo e ao lazer, os moradores que frequentam as reuniões da SAB Catolé, reivindicam mais e melhores espaços de lazer.

Assim, a reivindicação é muita, né? Porque é preciso, é muita criança aqui, e a gente não tem nenhuma, assim, principalmente os pais, muitos trabalha e as crianças ficam em casa, no meio das ruas sem ter o que fazer, então, brincando com o lixo, não tem um espaço adequado para se divertir (Presidente da $S A B$ Catolé).

Mesmo que o lazer, muitas vezes, não seja mencionado como prioridade, quando tocamos no assunto das políticas públicas, podemos perceber que os moradores do Catolé sentem a necessidade de que o seu cotidiano lúdico seja reorganizado, a partir da intervenção do Estado. Isso é importante, já que estamos tratando de um bairro em que as opção para o lazer são muitas, mas em sua maioria, relacionadas ao consumo de bens e serviços, como iremos discutir a seguir.

\section{Espaços e equipamentos públicos de lazer no Catolé}

Ao andarmos pelas ruas do Catolé, observamos um grande número de condomínios fechados, contrastando com áreas invadidas pela população, que em condições precárias de moradia, submete-se à falta de uma infraestrutura adequada de habitação. Paradoxalmente, o bairro é 
privilegiado pela sua diversidade de opções de lazer, que, em sua maioria, estão ligadas ao consumo dos mais diversos bens e serviços.

No Catolé, localizam-se inúmeras opções privadas de lazer, tais como: os dois principais shopping-centers da cidade. Além disso, encontramos várias casas de shows e muitas escolhas de gastronomia, $\mathrm{o}$ que chama atenção de diversos jovens para se reunirem nas panquecarias, pizzarias, bares e outros estabelecimentos do local.

As contradições existentes, no bairro do Catolé, refletem-se, então, nas experiências de lazer da população, já que as muitas opções de lazer ligadas ao consumo atraem não só pessoas das mais altas classes sociais da cidade ao bairro, mas também de camadas mais humildes.

Além de espaços e equipamentos públicos e privados, encontramos, no bairro, aqueles locais que não se situam em nenhuma dessas categorias, como as associações profissionais, que têm regras específicas para a utilização de suas dependências. O Serviço Social do Comércio - SESC, por exemplo, oferece atividades físicas durante a semana e nos finais de semana, se transformando-se em opção de lazer para seus associados.

É preciso, porém, o investimento em espaços e equipamentos públicos de lazer, gratuitos e de qualidade, para que a parcela de moradores do Catolé, que não mora nos condomínios de luxo do bairro, possa ter efetivado seu direito ao lazer.

Esses espaços devem ter aparência agradável, para despertar o desejo da população em frequentá-los nos seus momentos de lazer. Muitas vezes, porém, apenas o embelezamento do local, faz com que ele seja transformado meramente em um cenário para os pedestres, ao invés de um espaço de descanso, contemplação e entretenimento.

Um dos espaços de lazer encontrados, no Catolé, é a quadra localizada às margens da $\mathrm{SAB}$ do bairro. Nesta área, existiam duas quadras que pertenciam à $\mathrm{SAB}$, sendo que uma delas foi vendida para a construção do estacionamento de um shopping-center da cidade e não se sabe no que o valor adquirido foi revertido. Neste aspecto, observamos a perda de mais um local para a iniciativa privada, reduzindo cada vez mais as oportunidades e as ofertas de opções de lazer para as populações mais humildes. 
Percebemos que, no bairro do Catolé, há um grande investimento nos espaços privados de lazer, o que desperta a atenção de muitos moradores da cidade. Por outro lado, as políticas públicas de lazer precisam de uma melhor atenção para promover a inclusão e a participação popular nas experiências de lazer.

A outra quadra da SAB ficou como um espaço livre para a população, no entanto, nessa quadra, nunca foi realizada nenhuma reforma para melhorar o piso, as traves e a área que cerca a quadra, como apontam alguns moradores e a gestora da instituição. Consequentemente, este espaço serve de depósito de lixo e restos de materiais de construção, o que ocasiona muitas queixas dos moradores circunvizinhos. Além do perigo que proporciona à saúde das crianças que brincam próximo ao lixo.

Segundo relato de um morador, ao lado da quadra, em uma grande área livre, também, era depositado lixo. Por iniciativa de outros moradores, foram plantadas árvores e colocados bancos para evitar uma maior poluição ambiental, que se reverte em danos de saúde para os próprios moradores. Essa iniciativa da população local foi de suma importância, pois os moradores do bairro também são responsáveis por um ambiente harmônico, juntamente com o poder público.

A prefeitura... vem. Fazem a limpeza do lixo. No dia seguinte já tem lixo. Então é preciso ter a reeducação da própria população para que elas se conscientizem de que eles e também a gente tem um pouco de atenção maior por causa dos governos... se a gente tira o lixo, e a própria população volta a colocar o lixo, por que não fazer outras medidas? Calça o pedaço de rua que tá ai, pra calçar, faz a revitalização do piso dessa quadra, eu acho que não tem muito custo quanto a limpeza frequente do lixão, e isso a gente pede, a gente reivindica, grita... (Presidente da SAB Catolé).

Alertando o poder público a tomar medidas que reduzam custos frequentes com a limpeza, de forma a beneficiar a população e ter uma estratégia da mesma não retornar a colocar lixo nesses locais, a SAB local consegue cumprir o seu objetivo de ser mediadora entre o Estado 
e a população, sem onerar os cofres públicos ou culpabilizar os moradores locais.

Outros espaços utilizados pelas crianças para suas brincadeiras são as ruas e os terrenos baldios do bairro. Assim, observamos principalmente, no final da tarde, a concentração delas em torno do futebol, da amarelinha ou das pipas, divertindo-se e se relacionando com as outras crianças. Como menciona a presidente da $\mathrm{SAB}$, quando questionamos os locais que as crianças brincam no bairro "nesse espaço aqui em frente e aqui ao lado da lavanderia tem um jogo de futebol toda tarde pelas crianças". Enquanto isso, alguns adultos ficam conversando nos bancos da praça, localizados ao lado da SAB.

Em relação aos espaços e equipamentos da escola investigada, encontramos uma quadra que, no momento, está sem areia. A outra quadra está com o piso em má conservação. Na escola também tem um playground de alvenaria, construído recentemente. De acordo com a diretora da escola, o Instituto Alpargatas está analisando a possibilidade de reforma da quadra, que terá traves, será pintada e também terá arquibancadas.

Ainda conforme a diretora, mesmo com carência de manutenção dos espaços e equipamentos existentes na escola, muitas crianças chegam cedo e saem mais tarde, para aproveitarem estes espaços. Notamos, então, a necessidade das crianças em vivenciarem o lúdico e a atração que os espaços fornecidos pela escola proporcionam a elas, fazendo com que sintam a vontade de permanecer dentro do ambiente escolar.

A seguir, apresentamos mais alguns dos espaços e equipamentos para o esporte recreativo e o lazer, existentes no bairro do Catolé. 
Tensões e contradições no cotidiano lúdico do Catolé

\begin{tabular}{|c|c|c|}
\hline Tipo & Quantidade & Condições de uso \\
\hline $\begin{array}{c}\text { Quadra em frente a SAB } \\
\text { Catolé }\end{array}$ & 1 & $\begin{array}{c}\text { Piso com buracos. Lixo } \\
\text { depositado ao lado. }\end{array}$ \\
\hline $\begin{array}{c}\text { Quadras do Parque da } \\
\text { Criança }\end{array}$ & 3 & $\begin{array}{c}\text { Piso desnivelado e redes } \\
\text { de proteção danificadas. }\end{array}$ \\
\hline $\begin{array}{c}\text { Playgrounds do Parque } \\
\text { da Criança }\end{array}$ & 2 & Faltam alguns balanços no playground \\
de madeira.
\end{tabular}

Quadro 1 - Espaços e equipamentos para o esporte recreativo e o lazer, existentes no Catolé

Alguns espaços e equipamentos não foram citados pelos gestores entrevistados. Consideramos necessário que os gestores das SABs e das escolas do bairro, reconheçam o cotidiano lúdico do Catolé, para que desse modo possam motivar e informar a população sobre as diversas manifestações culturais que são vivenciadas no local.

\section{Manifestações culturais presentes no bairro do Catolé}

Compreendemos o lazer como uma dimensão da cultura, sendo esta um conjunto de hábitos que conduz a vida da sociedade, variando de lugar para lugar (MELO; ALVES JÚNIOR, 2003). Sendo assim, é caracterizada pelas tradições e experiências vivenciadas pela população, que se expressa através dos movimentos corporais, vestimentas e músicas, entre outros aspectos. 
Segundo relato da presidente da SAB Catolé e da escola municipal visitada, no bairro, são comemoradas as festividades do Dia das Mães, dos Pais, São João e dia das Crianças, entre outras, que são organizadas pela escola e pela SAB. No dia das Mães e dos Pais, são realizadas homenagens. No São João, há quadrilhas para as crianças. A SAB recebe apoio de alguns comerciantes, empresários da cidade, prefeitura e governo do estado. No quadro a seguir, destacamos mais algumas das manifestações culturais e dos eventos existentes no bairro do Catolé.

\begin{tabular}{|c|c|c|}
\hline $\begin{array}{c}\text { Manifestações culturais } \\
\text { e eventos }\end{array}$ & Formas de vivência & Temporalidade \\
\hline Capoeira & $\begin{array}{c}\text { Aulas de Capoeira para } \\
\text { as crianças dos turnos } \\
\text { da manhã e da tarde }\end{array}$ & Semanal \\
\hline Dança & $\begin{array}{c}\text { Apresentação das qua- } \\
\text { drilhas da escola }\end{array}$ & $\begin{array}{c}\text { Mês de junho no São } \\
\text { João }\end{array}$ \\
\hline Boi de Carnaval & $\begin{array}{c}\text { Ensaio nas ruas e } \\
\text { na SAB }\end{array}$ & $\begin{array}{c}\text { Mês de Fevereiro e } \\
\text { no Carnaval }\end{array}$ \\
\hline Futebol & Partidas realizadas pelas \\
crianças & $\begin{array}{c}\text { Todos os finais da } \\
\text { tarde }\end{array}$ \\
\hline $\begin{array}{c}\text { Dia das mães, dos pais, das crian- } \\
\text { ças e São João }\end{array}$ & Festividades & Uma vez por ano \\
\hline
\end{tabular}

Quadro 2 - Manifestações culturais e eventos existentes no bairro do Catolé

Os eventos oferecidos pela SAB atraem a população do bairro em geral. Nestes, são realizados distribuição de brindes, passeios, lanches, serestas, aumentando, assim, o interesse e participação da comunidade, que muitas vezes só vem à $\mathrm{SAB}$ por meio desses eventos.

Talvez a população não vá às reuniões mensais da SAB Catolé, por acreditar que sua presença, nas reuniões, não irá contribuir para um melhor funcionamento do bairro. Já nos eventos, existe algo imediato a receber, motivando assim a sua presença.

No carnaval, há alguns anos, é desenvolvido um trabalho com as crianças, no qual é realizado o "Boi de Carnaval". Um boi identificado, 
no bairro, foi o "boi dengoso" (NASCIMENTO; LEMOS, 2006). As crianças, com a ajuda de moradores do bairro, confeccionam suas fantasias, utilizando o espaço da SAB ou a quadra para ensaios e se apresentam, nas ruas do próprio bairro do Catolé, no período carnavalesco. Esses eventos são realizados com recursos dos próprios moradores.

As brincadeiras de rua também se caracterizam como manifestações culturais e estão presentes no cotidiano do bairro do Catolé. A rua é um espaço de partilha tanto do aprendizado quanto da interação entre as crianças. Essas brincadeiras têm intuito de manter viva a história, as tradições e as raízes de uma cultura (ZACARIAS, 1999).

Dessa forma, apontamos a necessidade de políticas públicas de lazer, que propiciem a preservação das brincadeiras de rua como a amarelinha, as competições de bola de gude e a pipa, observadas no cotidiano lúdico do Catolé.

\section{Considerações finais}

Em linhas gerais, são notórios os paradoxos existentes no Catolé. Por um lado, inúmeras formas de lazer são ligadas ao consumo. Por outro lado, percebemos a desigualdade na distribuição dos espaços e equipamentos públicos de lazer do bairro, visto que por ter uma grande extensão territorial, talvez alguns dos seus próprios moradores não tenham condições de se deslocarem para esses lugares.

Para que as atividades de lazer futuramente não estejam apenas vinculadas ao consumo, devido ao crescimento de espaços privados de lazer e a deficiência da infraestrutura de espaços públicos, é preciso que a sociedade seja participante na construção do direito ao lazer para todos os cidadãos, para que dessa forma, o lazer possa contribuir para a transformação social.

Parafraseando Maia e Costa (2008), é necessário que as prefeituras, secretarias e órgãos públicos, de forma geral, procurem saídas para que os espaços públicos de lazer tenham as transformações e adaptações viáveis às necessidades da população. Para tanto, é funda- 
mental uma melhor atenção da sociedade quanto às políticas públicas em geral da cidade.

Neste sentindo, torna-se importante uma melhor comunicação entre os órgãos governamentais, para juntos construírem uma melhor elaboração de políticas públicas voltadas ao lazer, que beneficiem toda a comunidade. Através do contato com a SAB do Catolé, percebemos a existência de moradores que ainda acreditam em suas reivindicações, que são de suma importância para mostrar às autoridades suas necessidades quanto ao lazer, dentre outras necessidades.

Portanto, torna-se essencial que os gestores, em geral, tenham conhecimento da importância do lazer e das reivindicações da população, de forma a estabelecer parcerias entre a comunidade e o poder público, principalmente para a conservação dos espaços e equipamentos de lazer (CHEMIN, 2007).

Em síntese, é necessário discutir e fomentar políticas públicas que propiciem uma educação para o lazer, de forma que os indivíduos reflitam e ocupem o seu tempo livre da melhor maneira possível, reconhecendo o cidadão ao seu lado não como um estranho ou um inimigo, mas como alguém que, apesar de diferente, pode caminhar junto conosco, em direção ao bem comum.

\section{Referências}

BAUMAN, Z. Confiança e medo na cidade. Tradução Eliana Aguiar. Rio de Janeiro: Jorge Zahar, 2009.

BETTI, M.; ZULIANI, L. R. Educação Física escolar: uma proposta de diretrizes pedagógicas. Disponível em: <http://www.mackenzie.br/fileadmin/Graduacao/CCBS/Cursos/Educacao_Fisica/REMEFE-1-1-2002/ art6_edfis1n1.pdf>. Acesso em: 03 fev 2009.

CHEMIN, B. F. Políticas públicas de lazer: o papel dos municípios na sua implementação. Curitiba: Juruá, 2007. 
IBGE - Instituto Brasileiro de Geografia e Estatística. Censos Demográficos 1991/2000. 2002.

INSTITUTO ALPARGATAS. Projeto Escola Ideal. Disponível em: <http:// www.institutoalpargatas.com.br/index.php?escola-ideal_4>. Acesso em: 14 abr 2009.

JORNAL DA PARAÍBA. Catolé já se consolida como pólo comercial e de entretenimento. Jornal da Paraiba. 11 de Junho de 2006.

MAIA, L. F. S.; COSTA, L. K. S. A auto-organização comunitária e o trabalho coletivo dos usuários do Programa Esporte e Lazer da Cidade: um olhar sobre a realidade dos núcleos de Natal.Seminário O Lazer em Debate, 9., 2008 São Paulo, Anais... São Paulo, 2008. CD-ROM.

MARCELlinO, N. C. Lazer e Humanização. Campinas: Papirus, 1995.

MELO, V. A.; ALVES JÚNIOR, E. D. Introdução ao lazer. Barueri: Manole, 2003.

NASCIMENTO, S. Q.; LEMOS, E. M. B. C. A dança popular nas comunidades de bairro: conhecendo a arte dançante em Campina Grande. Campina Grande: PIBIC/CNPq/UEPB, 2006.

RECHIA. S. A política de lazer na cidade: em pauta: “a análise da gestão dos espaços em distintas realidades e segmentos populacionais. Encontro Nacional de Recreação e Lazer,20., 2008, São Paulo. Anais... São Paulo, 2008. CD-ROM.

TORO, J. B.; WERNECK, N. M. D. Mobilização social: um modo de construir a democracia e a participação. Belo Horizonte: Autêntica, 2007.

União Campinense das Equipes Sociais. Estatuto. Campina Grande, 2006. Disponível em: < http://www. ucescg.com.br/estatutos.html> Acesso em: 18 jan 2009.

ZACARIAS, L. S. Crianças no mundo da rua: socialização, cultura e gênero. Dissertação (Mestrado) - Universidade Estadual de Campinas, Faculdade de Ed. Física. Campinas, 1999. 